\title{
PRINCÍPIOS COOPERATIVISTAS SOB A PERSPECTIVA DE COLABORADORES DE UMA COOPERATIVA DE CRÉDITO
}

\author{
Cooperative Principles from the Perspective of Employees of a Credit Cooperative
}

\begin{abstract}
RESUMO
Esta pesquisa tem como objetivo analisar a prioridade dos princípios cooperativistas na percepção dos colaboradores de uma cooperativa de crédito. Para isso, aplicou-se um instrumento estruturado na coleta de dados com 99 (noventa e nove) colaboradores de uma cooperativa de crédito da Região Central do RS. Por meio do Método de Análise Hierárquica de Processos (AHP), priorizouse na visão deles, os critérios com o intuito de verificar quais dos Princípios Cooperativistas eram mais relevantes. Como principais resultados demonstrou-se que alguns princípios estão em destaque, como a "adesão livre e voluntária" e a "gestão democrática pelos associados", em relação aos demais, observou-se que são menos evidentes no contexto da cooperativa. Por fim, os resultados obtidos, haja vista disseminação de informações entre os membros da organização, bem como ampliação dos canais de participação e educação cooperativa, visando diminuir esta lacuna, junto a sociedade e sua gestão.
\end{abstract}

Andrieli de Fátima Paz Nunes

Universidade Federal de Santa Maria (UFSM)

andriieli.nunes@gmail.com

Deoclécio Junior Cardoso da Silva

Universidade Federal de Santa Maria (UFSM)

deocleciojunior2009@hotmail.com

Beatriz Leite Gustmann de Castro

Universidade Federal de Santa Maria (UFSM)

beatriz_gustmann@hotmail.com

Gabriel Murad Velloso Ferreira

Universidade Federal de Santa Maria (UFSM)

gabriel@ufsm.br

Vânia Medianeira Flores Costa

Universidade Federal de Santa Maria (UFSM)

vania.costa@ufsm.br

Recebido em: 06/08/2021. Aprovado em: 06/10/2021.

Avaliado pelo sistema double blind review

Avaliadora científica: Lindsay Teixeira Sant'Anna

DOI: $10.48142 / 2320211799$

This research aims to analyze the priority of cooperative principles in the perception of employees of a credit union. For this, a structured instrument was applied to data collection with 99 (ninety-nine) employees of a credit union in the Central Region of RS. Through the Method of Hierarchical Process Analysis (AHP), in their view, the criteria were prioritized in order to verify which of the Cooperative Principles were more relevant. The main results showed that some principles are highlighted, such as "free and voluntary membership" and "democratic management by members", in relation to the others, it was observed that they are less evident in the context of the cooperative. Finally, the results obtained, given the dissemination of information among the members of the organization, as well as the expansion of channels of participation and cooperative education, aiming to reduce this gap, with society and its management.

Palavras-chave: Cooperativismo; Colaboradores; Análise Hierárquica de Processos.

Keywords: Cooperativism; Contributors; Analytic Hierarchy Process.

\section{INTRODUÇÃO}

Em 1844, em meio a Revolução Industrial, um grupo de vinte e oito operários ingleses, moradores do distrito de Lancashire, fundou a cooperativa de consumo "Rochdale Society of Equitable Pionners", que tinha como objetivo buscar melhores formas para a situação econômica precária mediante auxílio mútuo entre os cooperados (Sales, 2010). Esta cooperativa ficou conhecida como a Sociedade dos Probos de Rochdale, considerada a primeira cooperativa da sociedade moderna. Sales (2010) explica 
ainda que o sistema de cooperação não nasce em Rochdale, mas ganha grande forma e seus princípios são, até hoje, considerados como a base do cooperativismo.

Além disso, cooperar, na visão de Gawlak e Rarzke (2010) é agir de forma coletiva com os outros, trabalhando juntos em busca do mesmo objetivo, e por meio da prática da cooperação é possível educar os indivíduos desenvolvendo uma mentalidade mais aberta, flexível, participativa, humana e solidária. Desta forma, o cooperativismo é visto como um modelo econômico e também como uma filosofia de vida, com condições de desenvolver uma região, de criar bem-estar social e de ser uma alternativa capaz de levar ao sucesso, com equilíbrio e equidade (Vronski \& Olimpio, 2016; Fuzinatto et al., 2019, Cunha et al., 2020).

Do mesmo modo, as cooperativas possuem, conforme destacam Meinen e Port (2014), direcionadores filosófico-doutrinários que podem ser representados, especialmente, por valores e princípios de adoção universal, de modo que, os valores precedam e dão origem aos princípios que, por sua vez, traduzam os valores e os levam à prática no meio cooperativo. Cabe destacar que não existe uma convergência absoluta em relação aos valores cooperativos, entretanto, Meinen e Port (2014, p. 28) fazem uma relação aos nove valores associados às cooperativas recorrentes na literatura: "solidariedade, liberdade, democracia, equidade, igualdade, responsabilidade, honestidade, transparência e responsabilidade socioambiental".

Além do mais, o sistema cooperativista possui um órgão representativo máximo, o International Cooperative Alliance-ICA, fundado em 1895, composto por cooperativas de diversos países. As suas principais atribuições são manter a identidade da cooperativa e competir no mercado, tendo como objetivo estratégico desenvolver fortes organizações cooperativas para o progresso local (Begnis et al., 2014; Fuzinatto et al., 2019). Já o ICA estabelece sete princípios norteadores que, embora revisados, permanecem os mesmos desde 1844, são eles: adesão livre e voluntária; controle, gestão democrática; participação econômica de seus associados; autonomia e independência; educação, formação e informação; intercooperação; preocupação com a comunidade (ICA, 2020).

Ainda, conforme definição legal, no Brasil, uma sociedade cooperativa origina-se na celebração de um contrato por pessoas que reciprocamente obrigam-se a contribuir com bens ou serviços para o exercício de uma atividade econômica, de proveito comum, sem objetivo de lucro. Ainda, no que se refere aos tipos de cooperativas, a legislação brasileira prevê que poderão adotar por objeto qualquer gênero de serviço, operação ou atividade, tendo por obrigação o uso da expressão “cooperativa” em sua denominação (Brasil, 1971).

No cenário brasileiro, o cooperativismo abrange diferentes ramos, sendo eles: produção de bens e serviços; infraestrutura; consumo; transporte; saúde; agropecuário; e crédito. A classificação das cooperativas brasileiras em ramos é necessária para que a Organização das Cooperativas do Brasil (OCB) organize-se internamente e otimize os esforços de suas equipes, com vista ao máximo de aproveitamento das ações de representação dos interesses dos cooperados junto aos Três Poderes da República (OCB, 2019).

Cabe salientar que o presente estudo se volta, especificamente, para uma cooperativa de crédito, as quais segundo o Banco Central do Brasil (2019) tiveram aumento significativo nos últimos tempos. Para Brandalize et al. (2021) além de prestação de serviços financeiros, um grande número de cooperativas de crédito também possui funções sociais relevantes. Conforme Freitas \& Freitas (2014) e Santos et al. (2020) acrescentam que, como alternativa social, as cooperativas de crédito buscam equilibrar seu desempenho financeiro e social, pois os superávits (ou seja, a lucratividade gerada pelos serviços e produtos financeiros) voltam para seus associados, o que mostra que a influência é mútua e cíclica. Por isso, esse aspecto afeta diretamente o crescimento dessas instituições, pois elas continuam crescendo economicamente e financeiramente, criando condições para expandir a atuação, o portfólio de produtos e os serviços financeiros (Freitas \& Freitas, 2014; Santos et al., 2020).

Diante das exposições feitas, este estudo tem como objetivo analisar a prioridade dos princípios cooperativistas na percepção dos colaboradores de uma cooperativa de crédito. Primeiramente, apresentou-se a introdução do estudo. Posteriormente, na segunda seção, é elucidado o referencial teórico. A terceira seção engloba o percurso metodológico para a operacionalizar a pesquisa. A quarta seção trata da apresentação e discussão dos resultados. Por fim, na quinta seção constam as considerações finais.

\section{COOPERATIVISMO}

A priori, colaborar é unir-se a outras pessoas com o intuito de enfrentar juntos situações adversas, transformando-as em oportunidades e situações de bem-estar econômico e social. Além disso, o cooperativismo é um movimento internacional, cujo intento é libertar o homem do seu individualismo por meio da auxilio entre as pessoas. Já a cooperativa é a organização de pelo menos vinte pessoas físicas, unidas por objetivos econômicos e sociais comuns. Por fim, associado ou cooperado são termos 
utilizados para designar a pessoa que, sendo sócio de uma cooperativa, recebendo vantagens advindas do auxilio entre todos os associados (Henock, 2019; Collin, 2020).

Para Moraes e Schwab (2019) o "cooperativismo é um sistema anticapitalista, e visa o combate ao monopólio, à disciplina dos setores de produção, ao consumo e crédito, podendo disseminar a outros campos de atividades". Em outros termos, o cooperativismo designa organização econômica que planeja eliminar os possíveis desajustes sociais oriundos das intermediações do sistema capitalista (Rodríguez e Almeida, 2021).

Por sua vez, no entendimento de Marchesan et al. (2019), o cooperativismo é entendido como uma doutrina econômica e social, que se fundamenta na liberdade, no humanismo, na democracia, na solidariedade, na igualdade, na racionalidade e no ideal de justiça social. A doutrina cooperativista surgiu no século XIX como resultado de um processo por meio do qual se procurava atenuar ou suprimir os desequilíbrios econômicos e sociais oriundos da Revolução Industrial. À vista disso, a doutrina cooperativista tem como finalidade a correção do social pelo econômico utilizando, para isso, sociedades de caráter democrático e solidário: as cooperativas.

Outrossim, o cooperativismo tem sua existência marcada na pré-história, na colheita, na pesca e na caça. Denota-sendo que a cooperação tem sido constante na vida do ser humano no decorrer dos tempos quando os homens se agrupam para defenderem interesses em comum (Rahmana et al. 2020). Além disso, conforme De Souza (2014) e Paes et al. (2019) enfatizam que o movimento cooperativista teve início na Inglaterra e França como oposição operária às consequências do liberalismo econômico praticado no fim do século XVIII e início do século XIX.

Do mesmo modo, com base nos estudos de Hu et al. (2021) a ajuda entre as pessoas é caracterizada pelo transcorrer da história humana. Assim, o desenvolvimento das sociedades, singularmente com a Revolução Industrial na Inglaterra, França e Alemanha, aumentou a exploração dos trabalhadores pelos proprietários das indústrias. Esses trabalhadores tinham uma jornada de trabalho exaustiva culminando 17 horas por dia e recebiam pouco, sendo o cooperativismo uma das reações destes indivíduos perante tal situação.

$\mathrm{Na}$ acepção de Rahmana et al. (2020) foi no século XIX que surgiram condições favoráveis para o cooperativismo na Europa, objetivando corrigir e reformar a economia, direcionando a ação dos homens. Esse acontecimento teve por consequência o avanço do liberalismo econômico e pela relevância da razão e da liberdade. Sendo assim, as cooperativas começaram a multiplicar-se pela influência de pensadores como Owen, William King, Buchez, Charles Gide e outros que buscavam uma organização social mais justa e equitativa (Piletti et al., 2015; Carneiro et al. 2018).

No tocante ao território brasileiro, o cooperativismo teve sua gênese por meio de influências do cooperativismo europeu. Pode-se dizer que o ideal autogestionário e associativista chegou ao país no século XVII, por meio da fundação das primeiras reduções jesuíticas (Alves, 2021). Além disso, o primeiro registro de uma cooperativa brasileira é de 1889, uma cooperativa de consumo em Minas Gerais, nominada Sociedade Cooperativa Econômica dos Funcionários Públicos de Ouro Preto (Alves, 2021).

Dessa forma, para que o cooperativismo seja efetivo é necessário que haja melhoria da situação econômica de seus membros. Todavia, objetivos sociais e culturais também são incorporados ao cooperativismo. Alves (2021) destaca que a solidariedade, democracia, humanismo, liberdade, igualdade, racionalidade e justiça social são pilares basilares do cooperativismo, assim a cooperativa busca desenvolver em seus associados esses valores, contribuindo para a sua educação como cidadãos e para a sua inclusão social. Além disso, é salutar mencionar que, o cooperativismo atenta-se para a melhoria de comunidades locais, inclusão financeira, erradicação da pobreza, bem como realiza campanhas responsáveis de recursos naturais, entre tantas outras similaridades em relação aos Objetivos de Desenvolvimento Sustentável (OCB, 2018).

Nesse sentido, o cooperativismo tem se destacado nos últimos anos no Brasil, estando presente em diversos setores econômicos. Assim, constata-se que são 7 (sete) ramos em que centralizam o cooperativismo em suas atividades, sendo: produção de bens e serviços; infraestrutura; consumo; transporte; saúde; agropecuário; e crédito (OCB, 2019). Todas são representadas pela Organização das Cooperativas Brasileiras (OCB) nacionalmente e pelas organizações estaduais (Oces) nas unidades da federação (OCB, 2018). Assim, todas as cooperativas possuem a mesma natureza jurídica e são orientadas por meio de sete princípios básicos do cooperativismo (Reus et al., 2015).

É mister salientar que, neste trabalho, o enfoque é o cooperativismo de crédito. O cooperativismo de crédito é formado por cooperativas destinadas a promover a poupança e financiar necessidades ou empreendimento dos seus associados. As cooperativas do ramo de crédito necessitam de autorização do Banco Central do Brasil para sua constituição, funcionamento e fiscalização (Bacen, 2019).

Desse modo, a criação de cooperativas de crédito de livre admissão de associados, por micros e pequenos 
empresários, foi possível a partir da Resolução 3.106 de 25/06/2003, do Banco Central do Brasil - BACEN, posteriormente, ampliada a médios e grandes empresários com a Resolução 3.140 de 27/11/2003 (Bacen, 2019). A partir da regulamentação do cooperativismo de crédito é possível observar a geração de trabalho e renda para a população, bem como a estimulação da expansão do microcrédito cooperativo.

Portanto, conforme foi destacado sobre o contexto do cooperativismo, é de suma importância tecer também acerca dos princípios do cooperativismo, o qual será objeto de análise do próximo tópico.

\section{PRINCÍPIOS DO COOPERATIVISMO}

As cooperativas são regidas por princípios cooperativistas regulados pela Aliança Cooperativa Internacional - ACI. Assim, os princípios cooperativistas são regras de conduta a serem seguidas pelos associados. A finalidade de criação dos princípios tem como base a necessidade de estabelecer normas para orientar a estrutura e o funcionamento das cooperativas (Bertuol et al., 2012; ACI, 2018).

Desse modo, Monteagudo (2001) e Carneiro (2017) mencionam que estes princípios surgiram com a criação da primeira cooperativa em Rochdale, Inglaterra, época em que acontecia a Revolução Industrial, e o nível de desemprego era cada vez mais alto, em virtude do trabalho artesanal que estava sendo substituído pelas máquinas. Assim, os tecelões de Rochdale organizaram-se para reagir ao capitalismo individualista e determinar sua sobrevivência seguindo lemas de liberdade, igualdade e fraternidade.

Sendo assim, os princípios cooperativistas foram evoluindo no decorrer das décadas, posto que, precisaram adequar-se à realidade de cada época e com a rotina da cooperativa, mas sempre mantendo a sua essência. Destarte, foi durante três congressos, em Paris (1937), em Viena (1966) e em Manchester (1995, que os princípios sofreram reformulações e atualizações. Em 1995, foi elaborada a declaração da identidade cooperativa que contém os valores e os princípios cooperativistas do movimento cooperativista global, o que contribui para orientar às empresas cooperativistas em suas operações de negócios diárias (ACI, 2018).

Dessa maneira, houve modificações dos princípios, ao longo dos anos, contudo, apesar das alterações o princípio da democracia permaneceu inalterado. $\mathrm{Na}$ acepção de Cançado et al. (2012) as mudanças ocorridas nos princípios cooperativistas podem ser interpretadas como um reforço as suas características e não um desvio a elas. Cabe ressaltar que, muitos dos princípios, como a democracia, por exemplo, estão presentes desde o início.
Assim, conforme a Aliança Cooperativa Internacional - ACI, com as modificações sofridas os princípios do cooperativismo são no momento sete, designados como: (1) Livre adesão e voluntária dos associados; (2) Controle democrático dos associados; (3) Participação econômica do associado; (4) Autonomia e independência; (5) Educação, treinamento e informação; (6) Intercooperação e (7) Preocupação com a comunidade (ACI, 2018). Na Figura 1 são feitas as descrições dos princípios citados:

Então, o princípio da livre adesão e voluntária dos associados, diz respeito à organização voluntária, aberta a todas as pessoas capazes de usar seus serviços e dispostas a aceitar as responsabilidades de seus membros, sem discriminação de gênero, social, racial, política ou religiosa (Cançado et al., 2014; Gomes \& Souza, 2018; ICA, 2020).

Já o controle democrático dos associados, consiste na participação ativa de seus membros na definição de suas políticas e na tomada de decisão. Ou seja, homens e mulheres que servem como representantes eleitos são responsáveis perante os membros. Nas cooperativas primárias, os membros têm direitos de voto iguais (um membro, um voto) e as cooperativas em outros níveis também são organizadas de maneira democrática (Cançado et al., 2014; ICA, 2020).

Desse modo, o terceiro princípio cooperativismo relativo à participação econômica do associado, alude a contribuição equitativa dos membros e controlam democraticamente o capital de sua cooperativa. Pelo menos parte desse capital é frequentemente propriedade comum da cooperativa. Já os membros geralmente recebem uma remuneração limitada, se houver, sobre o capital subscrito como condição para ser membro (Cançado et al., 2014; Gomes \& Souza, 2018; ICA, 2020).

Assim, as cooperativas são organizações autônomas de autoajuda controladas por seus membros. Se eles entrarem em acordos com outras organizações, incluindo governos, ou levantarem capital de fontes externas, eles o farão em termos que assegurem o controle democrático de seus membros e mantenham sua autonomia cooperativa (Cançado et al., 2014; ICA, 2020).

Conforme Cançado et al. (2014) o quinto princípio do cooperativismo refere-se à educação e treinamento para seus membros, representantes eleitos, gerentes e empregados, para que possam contribuir efetivamente para o desenvolvimento de suas cooperativas. A intercooperação frisa $o$ atendimento de seus membros de maneira mais eficaz para fortalecer o movimento cooperativo trabalhando juntos por meio de estruturas locais, nacionais, regionais e internacionais. Já o último princípio do cooperativismo refere-se à preocupação com a comunidade, no sentido 
do desenvolvimento de suas comunidades, por meio de políticas aprovadas por seus membros (Cançado et al., 2014; Gomes \& Souza, 2018; ICA, 2020).

Portanto, explanados os princípios que norteiam as cooperativas de créditos, é importante destacar que estudos realizados com o objetivo de avaliar o grau de aderência dos associados em relação aos princípios cooperativistas têm sido realizados, embora ainda de maneira menos aparente. A exemplo disso, Ribeiro e Melo (2020) desenvolveram um estudo em uma cooperativa de crédito em Minas Gerais e constataram que houve elevado grau de aderência, no que diz respeito aos princípios cooperativistas pelos associados.
Por fim, o estudo de Cunha et al. (2020) demonstrou que o cooperativismo de crédito busca de maneira contínua aplicar os princípios com a finalidade de gerar benefícios econômicos na região em que está inserida. Além disso, a adesão livre e gestão democrática se destacaram na percepção dos associados, no entanto, a participação econômica dos membros e autonomia e independência, são menos ostensivos.

Em suma, os princípios, aqui, explanados representam a identidade cooperativa mundialmente. Assim, o tópico seguinte tece sobre os procedimentos metodológicos.

Cuja essência reside no compromisso, na responsabilidade que todos têm com todos, fazendo a força do conjunto e assegurando o bem de cada um dos membros. É uma espécie de reciprocidade obrigacional, justificada pelo interesse comum. Ser solidário é praticar a ajuda mútua (esta, por vezes, aparece como valor autônomo), é cooperar por definição, é tomar o empreendimento sólido.

Liberdade
Está no direito de escolha pela entidade cooperativa, tanto na hora do ingresso como no momento da Está no dir eito de escollha pela entidade cooperativa, tanto na hora do ingresso como no momento da consciência, respeitados os limites estabelecidos coletivamente.

\section{Democracia}

Está diretamente relacionada ao pleno dir eito de o associado participar da vida da cooperativa em toda a sua dimensão, especialmente pela palavra e pelo voto, implicando, em contrapartida, respeito às decisões majoritárias. Indica também acesso universal, sem discriminação de qualquer espécie. E pela democracia que se exerce a cidadania cooperativa.
Manifesta-se, fundamentalmente, pela garantia da igualdade de direitos, pelo julgamento justo e pela impar cialidade, tanto em aspectos economicos como sociais

\section{Igualdade}

Impede a segregação em razão de condição socioeconômica, raça, gênero ou sexo, ideologia política, opçẫo religiosa, idade ou de qualquer outra preferencia ou caracteristica pessoal. A todos devem ser assegurados os mesmos direitos e as mesmas obrigações

Responsabilidade
Tem a ver com a assunç̃o e o cumprimento de deveres. Como cooperada a pescoa é responsável pela Tem a ver com a assunção e o cumprimento de deveres. Como cooperada, a pessoa é responsável pela
viabilidade do empreendimento, incumbindo-lhe operar com a cooperativa e participar das atividades sociais. Cada qual responde pelos seus atos, devendo conduzir-se com retidaro moral e respeito às regras de convívio adotadas coletivamente.

Honestidade
Liga-se à verdade por excelência. E uma das marcas de pessoas de elevado caráter. Tem a ver com retidăo, probidade e honradez. Dignidade, enfim.

Tr ansparência

Diz respeito à clareza, àquilo que efetivamente é, sem ambiguidade, sem segredo. No meio cooperativo, todos têm de ter conhecimento preciso sobre a vida da entidade: sua gestăo, seus números, suas regras.

\section{Responsabilidade Socioambiental}

Conecta-se ao compromisso do empreendimento cooperativo, naturalmente de caráter comunitário, com o bem-estar das pessoas e com a proteção do meio ambiente compreendidos na sua área de atuação, preocupação que envolve desenvolvimento econômico e social e respeito ao equilibrio e às limitações dos recursos naturais
}

FIGURA 1 - Princípios Cooperativos

Adaptado de ICA (2020) 


\section{MÉTODO}

No que se refere aos procedimentos metodológicos adotados, a pesquisa caracteriza-se como um estudo de cunho quantitativo, exploratório e descritivo. Desse modo, realizou-se uma coleta de dados de forma eletrônica (online), para 99 colaboradores de uma cooperativa de crédito, utilizando um questionário estruturado com 20 questões fechadas, durante o período de janeiro a abril de 2019. Com o intuito de estabelecer uma amostra confiável e representativa, sendo assim, calculou-se o mínimo para a análise dos dados, assim, considerando um erro amostral de 7\%, a amostra mínima seria de 92 respondentes, ao qual, ao final, da coleta de dados obtevese 99 respostas válidas.

Desse modo, para realizar o grau de prioridade dos princípios cooperativas para a população pesquisada, utilizou-se o método de Análise Hierárquica de Processos (AHP), proposto por Saaty, que vem sendo utilizado para problemas envolvendo a tomada de decisão com múltiplos critérios, em que ocorre a decomposição do problema em uma árvore de decisão, realizando as prioridades dos construtos, utilizando uma análise paritária dos critérios e subcritérios (Saaty, 2008; Min, 2010; Mastrocinque, 2020).

Para estabelecer a análise, em primeiro momento, cria-se uma árvore de decisão e uma matriz para a realização das comparações paritárias, utilizando a escala de grau de importância de 9 pontos, elaborado pelo autor do método AHP (Saaty, 2008), ou seja, os tomadores de decisão, compararam de forma par a par, cada um dos princípios, estipulando notas de importância que um princípio estabelecia em relação ao outro. Assim, a Tabela 1, apresenta a escala de grau de importância proposto por Saaty.

TABELA 1 - Escala de Saaty

\begin{tabular}{ccc}
\hline Escala & Avaliação & Recíproco \\
\hline Extremamente preferido & 9 & $1 / 9$ \\
Muito forte a extremo & 8 & $1 / 8$ \\
Muito fortemente preferido & 7 & $1 / 7$ \\
Forte a muito forte & 6 & $1 / 6$ \\
Fortemente preferido & 5 & $1 / 5$ \\
Moderado a forte & 4 & $1 / 4$ \\
Moderadamente preferido & 3 & $1 / 3$ \\
Igual a moderado & 2 & $1 / 2$ \\
Igualmente preferido & 1 & 1 \\
\hline
\end{tabular}

Fonte: Saaty (2008)
Assim, após o julgamento feito pelos tomadores de decisão, calcula-se os pesos de prioridade, por meio da média geométrica da linha da matriz, estabelece-se o autovalor e posteriormente o autovetor, dividindo o resultado do autovalor, pelo somatório dele mesmo, para que fosse possível verificar em termos percentuais, o grau que aquele critério representava no total (Saaty, 2008).

Por fim, realizado os julgamentos, calcula-se o índice de consistência. Já o indice de Consistência (IC) avalia o grau de inconsistência da matriz realizada par a par (Saaty, 2008), por meio da Equação 1:

$\mathrm{IC}=\frac{\left|\lambda_{\max }-\mathrm{N}\right|}{\mathrm{N}-1}$

Em que:

$\mathrm{N}$ : é a ordem da matriz.

$\lambda_{\max }$ : o maior autovalor da matriz de julgamentos paritários.

O cálculo do autovalor máximo é realizado com a utilização da tabela auxiliar (A"), gerada por meio da multiplicação da $1^{\mathrm{a}}$ coluna da matriz de julgamentos pela prioridade de A. O cálculo considera também um vetor de prioridades auxiliar P", cujo valor é obtido a partir da soma das linhas de A", dividindo os elementos do vetor P", pelos respectivos elementos do vetor de prioridades (Para auxiliar). $\lambda$ máx é calculo que utiliza a soma dos elementos armazenados em $\mathrm{P}$ auxiliar dividida pela ordem da matriz $(\mathrm{N})$.

A Razão de Consistência (RC) é o cálculo que permite avaliar a inconsistência em função dos julgamentos realizados, por meio da Equação 2:

$\mathrm{RC}=\frac{\mathrm{IC}}{\mathrm{IR}}$

Em que: IC é o Índice de Consistência e IR é o Índice Randômico (Random Index). Já o índice Randômico é percebido como o índice de consistência obtido para uma matriz randômica recíproca, apresentando elementos não-negativos, para diversos tamanhos de matriz N. Na Tabela 2 observa-se a ordem das matrizes e seus respectivos valores IR.

Assim sendo, para uma matriz de julgamentos ser considerada aceitável, o pesquisador necessita ter um IR com uma razão de consistência menor que ou igual a 10\%. Desse modo, o próximo tópico apresenta os resultados alcançados por meio da análise utilizando o método AHP. Salienta-se que para a realização dos cálculos utilizou-se o software Microsoft Excel.

Organizações Rurais \& Agroindustriais, Lavras, v. 23, e1799, 2021 
Desse modo, resume-se a aplicação do método da seguinte forma:

$1^{\mathrm{o}}$ - Os tomadores de decisão estipulam uma nota de prioridade ao comparar os princípios um com o outro, definindo qual é mais importante, a nota é dada com base na Tabela 1;

$2^{\circ}$ - Calcula-se os pesos a partir das etapas previstas pelo método AHP, evidenciando os graus de prioridade alcançados para cada um dos princípios (Saaty, 2008);

$3^{\circ}$ - É realizado o cálculo do $\lambda_{\text {max }}$ IC e RC, buscando verificar o nível de consistência, onde caso esteja consistente segue-se para a apresentação dos resultados.

\section{RESULTADOS E DISCUSSÃO}

Diante da aplicação dos questionários, obteve-se dados relacionados ao entendimento dos colaboradores quanto aos Princípios Cooperativos. Aplicando o método AHP pode-se identificar qual dos critérios é o mais relevante de acordo com a perspectiva dos colaboradores. Desse modo, a Tabela 3, evidencia as prioridades encontradas com a aplicação do método.

Assim, é possível observar, conforme a Tabela 3, a percepção dos colaboradores denota-se que, diante a esse pressuposto, o critério "Cr1 - Adesão voluntária livre" obteve maior grau de prioridade para estes colaboradores, o qual remete que qualquer indivíduo, desde que concorde com o Estatuto Social da Cooperativa e com os Princípios Cooperativos, possa ingressar. Outro fator válido a ressaltar é o critério priorizado pelos colaboradores para o critério " $\mathrm{Cr} 2$ - Gestão democrática pelos associados", demonstrando que as ações da cooperativa são feitas pelos sócios, em que cada membro tem direito a um voto. E é com base neste princípio, que se nota maior diferença entre cooperativas e empresas tradicionais.

$\mathrm{Na}$ concepção de Schneider (2012) uma das características que diferencia a cooperativa da empresa capitalista é o seu caráter democrático. Comparando-se a sociedade anônima, cada ação dá direito a um voto, em que converte os proprietários de grandes ações em donos práticos das referidas empresas. De maneira oposta, nas cooperativas, são os sócios que, com plena igualdade de votos, dirigem a empresa e não o capital.

Diante da apresentação dos resultados na Tabela 3, e buscando demonstrar graficamente, elaborou-se a Figura 02, a qual ilustra os resultados dos critérios:

Verifica-se na Figura 2, as diferentes percepções dos colaboradores no que se refere aos critérios voltados aos Princípios Cooperativos. Pode-se observar que os critérios voltados a Cr3 - Participação econômica dos associados, Cr4 - Autonomia e Independência e Cr5 Educação, Formação e Informação obtiveram o mesmo peso de priorização pelos colaboradores. A partir das análises realizadas, é possível inferir que a cooperativa necessita instigar e dar atenção a importância dos critérios mencionados, além de buscar diferentes estratégias para despertar o interesse e incentivar os colaboradores a entender a complexidade que cada um possui.

TABELA 2 - Índice de Consistência Randômica

\begin{tabular}{ccccccccccc}
\hline Dimensão da matriz & $\mathbf{1}$ & $\mathbf{2}$ & $\mathbf{3}$ & $\mathbf{4}$ & $\mathbf{5}$ & $\mathbf{6}$ & $\mathbf{7}$ & $\mathbf{8}$ & $\mathbf{9}$ & $\mathbf{1 0}$ \\
\hline Inconsistência aleatória & 0 & 0 & 0,58 & 0,9 & 1,12 & 1,24 & 1,32 & 1,14 & 1,45 & 1,49 \\
\hline
\end{tabular}

Fonte: adaptado de Saaty (2008)

TABELA 3 - Critérios priorizados pelos colaboradores

\begin{tabular}{lcc}
\hline \multicolumn{1}{c}{ Critérios } & Peso global dos critérios \\
\cline { 1 - 2 } Cr1 - Adesão Livre e Voluntária & $44 \%$ & $22 \%$ \\
Cr2 - Gestão democrática pelos associados & $9 \%$ & $\lambda \max =7,02(\mathrm{IC}=0,00 ; \mathrm{RC}=0 \%)$ \\
Cr3 - Participação econômica dos associados & $9 \%$ & $9 \%$ \\
Cr4 - Autonomia e Independência & $4 \%$ \\
Cr5 - Educação, Formação e Informação & $4 \%$ \\
Cr6 - Intercooperação & \\
Cr7 - Interesse pela comunidade & \\
\hline
\end{tabular}

Fonte: Dados da pesquisa 


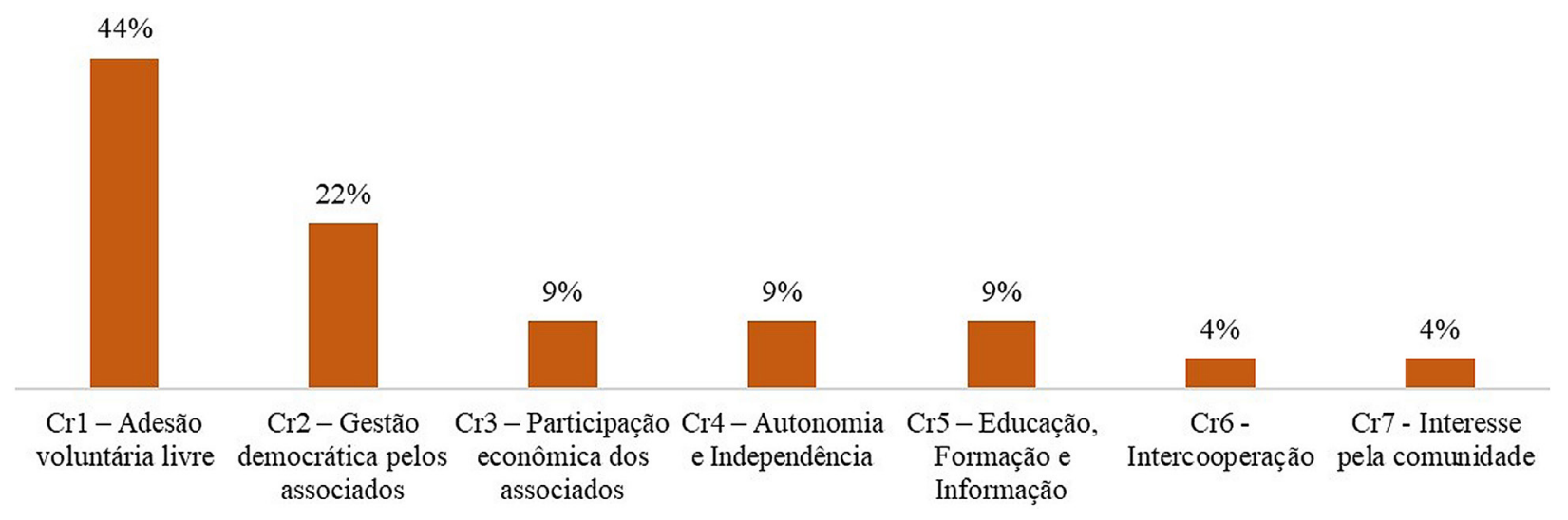

FIGURA 2 - Resultados acerca da percepção dos Colaboradores Fonte: Dados da pesquisa.

Além disso, verifica-se peso igual para os critérios Cr6 - Intercooperação e Cr7 - Interesse pela comunidade, o que denota que a cooperativa deve dar atenção para este resultado, visto que, conforme Silva et al. (2020, p. 8) "ao realizarem ações conjuntas, as cooperativas podem potencializar o impacto de ações por meio da colaboração" intensificando suas relações externas com demais cooperativas. Quanto ao princípio "Interesse pela comunidade" cabe lembrar que, este foi o último princípio a ser incorporado pela Aliança Cooperativa Internacional (ACI), no ano de 1995, enquanto os outros já eram estudados anteriormente. Este é um princípio importante, pelo fato de valorizar o local onde a cooperativa está situada, como também as comunidades em seu entorno (Silva et al., 2020).

O critério “Adesão Livre e Voluntária", conforme a ACI (2018), refere-se ao fato de as cooperativas serem voluntárias, abertas a todas as pessoas que queiram utilizar seus serviços e estejam dispostas a assumir responsabilidades como membros, sem discriminação social, racial, política ou religiosa. Cunha et al. (2020) ressaltam que esse princípio é fortalecido na prática de gestão da cooperativa, pois o número de associados não é limitado e o sistema acionário da cooperativa movimenta uma cota de capital inicial de integralização em torno de $\mathrm{R} \$ 20,00$ (vinte reais), valor relativamente baixo e, assim, abrangendo àqueles que pretendem associar-se à cooperativa de crédito.

Desse modo, sobre o critério "Gestão democrática pelos associados", as cooperativas são organizações democráticas controladas por seus associados, que participam ativamente da formulação de suas políticas e decisões. Nas cooperativas, os membros têm direitos iguais de voto, no qual cada membro, equivale a um voto (ACI, 2018). No estudo realizado por Gomes e Souza (2018) em uma cooperativa de crédito sobre os princípios cooperativistas, os autores argumentam acerca da relevância do conhecimento cooperativista e sobre informações relacionadas com sua cooperativa, tais como, o estatuto social e a participação das assembleias.

Segundo Oliveira et al., (2016) em uma cooperativa que há uma gestão democrática, os cooperados dividem responsabilidades, participam do estabelecimento de objetivos e metas, debatem decisões e traçam os rumos ao negócio. Assim sendo, prevalece a discussão de ideias, o respeito pela opinião alheia, a aceitação de experiências vivenciadas pelos outros, tudo baseado em um diálogo aberto e franco.

No que tange ao critério "Participação econômica dos associados", o qual é referenciado por Cançado et al. (2014) afirmando que este princípio se refere à contribuição dos associados que, controlam de forma democrática, o capital da cooperativa. Sabe-se que, os cooperados contribuem para a formação do patrimônio da cooperativa, por meio de reservas ou pelo capital social. Além disso, os cooperados têm o dever de operar com a sua cooperativa, uma vez que, são donos. Em contrapartida, existem certas vantagens, seja pela qualidade do atendimento, seja por preços especiais, ou então, pela distribuição dos resultados proporcionais às suas transações (Cooperativismo Financeiro, 2020).

Desse modo, sobre o critério "Autonomia e Independência", a ACI (2018) argumenta que o princípio em questão está atrelado a valores democráticos, transparentes e honestos. Além disso, significa que os membros das cooperativas têm direito a tomar decisões sobre as suas cooperativas, porém, as cooperativas financeiras, são supervisionadas seja pelo Conselho Monetário Nacional ou o Banco Central do Brasil (Cunha et al., 2020). 
No trabalho em questão, constata-se que apenas 9\% dos colaboradores consideram a Cooperativa " $\mathrm{Cr} 4$ Autonomia e Independência”, evidencia-se que é necessário promover encontros com os membros da cooperativa, com a intenção de disseminar informações, principalmente, em relação aos princípios, uma vez que, é importante que todos tenham entendimento sobre os fundamentos da cooperativa. Dessa forma, a autonomia e a independência denotam que as cooperativas são instituições autônomas, controladas por todos os seus membros, buscando atuar com a ajuda mútua e a gestão democrática (Silva et al., 2012).

Nesse sentido, o quinto critério refere-se à "Educação, Formação e Informação" que rege as cooperativas para que promovam a formação dos seus membros e colaboradores, informando ao público, em geral, sobretudo, os jovens e os líderes de opinião, sobre a natureza e as vantagens da cooperação (Cunha et al., 2020).

Além do mais, sobre o critério "Educação, Formação e Informação", verificou-se que há baixo índice de percepção dos colaboradores relacionado a este item. Sendo assim, denota-se a premência de realizar um trabalho de envolvimento com os colaboradores, a fim de buscar maior envolvimento com as políticas da cooperativa e integralização dos princípios visando a obter maior participação dos colaboradores.

Sob o ponto de vista de Gomes e Souza (2018) é por meio deste princípio que, evidencia-se a importância da disseminação do conhecimento cooperativista, para os indivíduos e sociedade, desenvolvendo aprendizagens quanto aos direitos e deveres como sócios, a cooperação e às ideias cooperativas, promovendo melhorias seja na abrangência da cooperativa, como expandindo para a comunidade a qual faz parte.

Deste modo, a "Intercooperação" refere-se às alianças entre as cooperativas, como forma de desenvolver o cooperativismo e também a busca de melhor qualidade dos serviços (ACI, 2018).

Esta assistência e cooperação mútua é uma forma de praticar o valor da solidariedade, conforme o interesse de uma cooperativa desenvolver e manter outra, seja de seu mesmo ramo ou dos demais. Partindo deste pressuposto, nota-se que o nível de $4 \%$ ainda está muito aquém do que precisaria ser, visto que, as relações entre cooperativas tendem a fortalecer o sistema na busca de conhecimento, na gestão, na troca de experiências, na troca de conhecimentos e na cooperação entre os membros e cooperativas.

Por fim, este resultado indica que há um desconhecimento e até mesmo, a inexistência da intercooperação das cooperativas. Assim, sugere-se o fortalecimento destas redes para fortalecer o movimento cooperativo, por meio do trabalho conjunto das estruturas locais, regionais, nacionais e internacionais. Nas cooperativas de crédito, a intercooperação ocorre também por meio de convênios, trocas financeiras, prestação de serviços aos associados de outras cooperativas, entre tantos outros benefícios como cartões de crédito, que permitem transações financeiras, depósitos e saques. Todavia, durante a análise desse princípio pelas cooperativas é que não há competição entre as cooperativas de um mesmo sistema, mas sim esforços em busca de um desenvolvimento igualitário (Cooperativismo Financeiro, 2020).

De acordo com os valores de ajuda mútua, responsabilidade, democracia, igualdade, equidade e solidariedade, as cooperativas foram criadas com um propósito inicial de defender e proteger o sustento de comunidades das imperfeições do mercado, a partir destes elementos foi criado o sétimo princípio elencado como "Interesse pela comunidade" (Cook \& Plunkett, 2006).

A partir dos resultados obtidos, no presente estudo, verificou-se que o "Cr7 - Interesse pela comunidade", na percepção dos colaboradores obteve $4 \%$, considerando um índice baixo. Contudo, é possível observar que algumas cooperativas, não têm esse critério como prioridade, em razão da falta de recursos para destinação para este fim. Fundamentado, a partir dos dados, é possível aferir que a cooperativa precisa melhorar sua comunicação com colaboradores, cooperados e demais membros da comunidade, a fim de disseminar da melhor forma a informação. Além disso, promover a ampliar a percepção da comunidade, em geral, para a importância das ações prestadas pela cooperativa, por meio de seus princípios que são os pilares que norteiam todo o funcionamento da cooperativa.

Em suma, conclui-se conforme, Schneider (2012, p. 269) que o "cooperativismo procurará colocar seu poder de "capilaridade social", capaz de marcar presença em cada rincão e aldeia rural ou em cada quarteirão urbano, onde os associados vivem, convivem e trabalham, enfim, onde tem plantadas as suas raízes". Após explanação sobre a discussão dos resultados, na seção seguinte, abordam-se as considerações finais deste estudo.

\section{CONSIDERAÇÕES FINAIS}

O presente estudo teve como objetivo analisar a prioridade dos princípios cooperativistas na percepção dos colaboradores de uma cooperativa de crédito, utilizando um questionário estruturado com 20 questões fechadas, coletou-se os dados de colaboradores de uma cooperativa de crédito acerca dos Princípios Cooperativos. 
Diante dos resultados expostos, analisados utilizando o método AHP, foi possível constatar que referente ao "Cr1 - Adesão Livre e Voluntária" e o "Cr2 - Gestão democrática pelos associados", são os mais percebidos pelos colaboradores, em que estes são notados na prática. Assim, mostra-se que existem muitas ações na cooperativa que estão embasadas nestes princípios e que são prontamente alinhados para a constante melhoria.

Além disso, correspondente ao " $\mathrm{Cr} 3$ - Participação econômica dos associados", "Cr4 - Autonomia e Independência" e "Cr5 - Educação, Formação e Informação", observou-se que são pouco percebidos pelos colaboradores. Tais informações podem ser interpretadas pela ausência de maior envolvimento entre cooperativa, colaboradores, cooperados e comunidade, em que surgem lacunas de disseminação de conhecimento e informação, entre os membros que estão inter-relacionados.

Desse modo, os critérios "Cr6 - Intercooperação" e "Cr7 - Interesse pela comunidade", caracterizaram-se pela baixa percepção dos colaboradores, enfatizando que, estes princípios são reconhecidos, no entanto, direcionam-se de maneira mais sutil e pouco notável pelos membros da cooperativa. Esses dados reforçam a importância da comunicação e entendimento dos princípios, correlacionando-os na prática da cooperativa.

De maneira geral, conclui-se que os princípios cooperativistas são aplicados no âmbito da cooperativa e constituem a base ética de seu sistema. Porém, alguns princípios são pouco propagados no ambiente da cooperativa, ocasionando lacunas expressivas de ausência de conhecimento por parte da gestão e sociedade cooperada.

Sendo assim, as análises deste estudo evidenciam a necessidade de maior interação do conhecimento da Cooperativa para com os seus membros e comunidade, a fim de gerar a criação de uma cultura em relação ao cooperativismo, estendendo seus benefícios à comunidade local. Paralelamente, às práticas de melhoria da comunicação devem ser ampliadas também aos canais de participação, com o intento de envolver os membros da cooperativa. Desse modo, como limitações, pode-se destacar a questão da quantidade de respondentes, bem como, a quantidade de instituições que foram analisadas.

Portanto, para estudos futuros, sugere-se o aprofundamento no conhecimento da aplicação dos princípios, sob a perspectiva da aplicabilidade na percepção da comunidade cooperativa, envolvendo colaboradores, gestores, associados e membros da comunidade.

\section{AGRADECIMENTOS}

Agradecemos pelo apoio dispendido da Coordenação de Aperfeiçoamento de Pessoal de Nível Superior (CAPES) que financiou por meio de bolsas de pesquisa o presente estudo.

\section{REFERÊNCIAS}

Aliança Cooperativa Internacional (ACI). (2018). O movimento das cooperativas por um Brasil melhor. Disponível em: https://www.ocb.org.br/. Acesso em: 09 abr. 2021.

Alves, G. B. (2021). Incidência de normas concorrenciais em cooperativas: a intervenção estatal sobre Cooperativas no Brasil. Deusto Estudios Cooperativos, (17), 43-74.

Banco Central do Brasil (BACEN). O que é cooperativa de crédito? Disponível em: https://www.bcb.gov.br/ estabilidadefinanceira/cooperativacredito. Acesso em: 27 set. 2021.

Banco Central do Brasil (BCB). (2021). Legislação. Disponível em: <www.bcb.gov.br>. Acesso em: 10 abr. 2021.

Begnis, H. S. M., Arend, S. C., \& Estivalete, V. D. F. B. (2014). Em frente ao espelho: a produção do conhecimento em cooperativas na Revista de Economia e Sociologia Rural. Revista de economia e sociologia rural, 52, 99116.https://doi.org/10.1590/S0103-20032014000100006

Bertuol, R., Cançado, A. C., \& Souza, M. D. F. A. (2013). A prática dos princípios cooperativistas: um estudo de caso no Tocantins. Amazônia, Organizações e Sustentabilidade, 1(2), 7-18. https://doi.org/10.17800/22388893/aos.v1n2p7-18

Brandalize, T., Flach, L., \& Sallaberry, J. D. (2021). Análise dos determinantes no grau de evidenciação do risco de crédito em centrais de cooperativas de crédito. Revista de Gestão e Organizações Cooperativas, 8(15), 01-34. https:// doi.org/10.5902/2359043242461

Brasil. (1971). Lei n. 5.764, de 16 de dezembro de 1971. Define a Política Nacional de Cooperativismo, institui o regime jurídico das sociedades cooperativas, e dá outras providências. Diário Oficial da União, Brasília, DF, 16 dez. 1971. Disponível em: <http://www.planalto.gov.br/ CCivil_03/leis/L5764.htm>. Acesso em: 10 abr. 2021. 
Cançado, A. C., Rigo, A. S., Pereira, J. R., \& Gontijo, M. C. H. (2012). Movimento e princípios cooperativistas: evolução e reflexões para novos estudos. Gestão Social: aspectos teóricos e aplicações. Ijuí: UNIJUÍ.

Cançado, A. C., Souza, M. D. F. A., \& Pereira, J. R. (2014). Os princípios cooperativistas e a identidade do movimento cooperativista em xeque. Revista de Gestão e Organizações Cooperativas, 1(2), 51-62. https://doi. org/10.5902/2359043216279

Carneiro, C. A. P. (2017). A operacionalização dos princípios cooperativistas sob a ótica da sustentabilidade 2017. Dissertação. (Mestrado em Administração). Programa de Pós-Graduação em Administração. Campo Grande - MS.

Carneiro, C. A., Moura-Leite, R. C., \& Arruda, A. (2018). A operacionalização dos princípios cooperativistas sob a ótica da sustentabilidade. Revista Metropolitana de Governança Corporativa (ISSN 2447-8024), 3(2), 54-70.

Collin, P. (2020). Selbstregulierung des Wettbewerbs. Konkurrenz und Kooperation von Sparkassen, Banken und Kreditgenossenschaften im frühen 20. Jahrhundert. Rechtsgeschichte-Legal History Rg, 28, 215-230.

Cook, M. L., \& Plunkett, B. (2006). Collective entrepreneurship: an emerging phenomenon in producerowned organizations. Journal of Agricultural and applied Economics, 38(2), 421-428. https://doi.org/10.1017/ S1074070800022458

Cooperativismo Financeiro. (2020). Os sete princípios universais que regem o Cooperativismo. Disponível em: $<$ https://cooperativismodecredito.coop.br/cooperativismo/ historia-do-cooperativismo/os-7-principios-docooperativismo/>. Acesso em: 13 abr. 2021.

Cunha, V. C., Galli, L. C. D. L. A., Prates, G. A., Savi, A. F., \& Santana, E. A. (2020). Análise dos princípios do cooperativismo aplicados nas cooperativas de crédito. SITEFA-Simpósio de Tecnologia da Fatec Sertãozinho, 3(1), 302-312.

da Cunha, V. C., Galli, L. C. D. L. A., Prates, G. A., Savi, A. F., \& Santana, E. A. (2020). Análise dos princípios do cooperativismo aplicados nas cooperativas de crédito. SITEFASimpósio de Tecnologia da Fatec Sertãozinho, 3(1), 302-312. https://doi.org/10.33635/sitefa.v3i1.121 da Silva, G. P., \& Oliveira, J. B. (2016). Gestão democrática na cooperativa de empreendimentos solidários do município de boa vista-coofec'S. Revista de Administração de Roraima-RARR, 6(3), 582-604.

de Freitas, A. F., \& de Freitas, A. F. (2014). O cooperativismo de crédito no Brasil e a emergência de uma vertente solidária. Revista Brasileira de Gestão e Desenvolvimento Regional, 10(2)..

de Souza Mazza, V. M. (2014). Cooperativismo e sustentabilidade: um estudo sobre a produção científica na base web of Science. Revista de gestão e organizações cooperativas, 1(1), 12-22. https://doi. org/10.5902/2359043215486

dos Santos, R. R., Callado, A. L. C., \& dos Santos, J. F. (2020). Folga Organizacional, Rentabilidade e Características de Cooperativas de Crédito Nordestinas. Revista Ciências Administrativas, 26(2).

Fuzinatto, N. M., Cassol, F. E., Batista, C., \& Bernardy, R. J. (2019). Os impactos do cooperativismo de produção no desenvolvimento de pequenos municípios. Gestão $e$ Sociedade, 13(35), 2901-2929.https://doi.org/10.21171/ ges.v13i35.2551

Gawlak, A.,\& Rarzke, F. (2010). Cooperativismo Primeira Lições. EditoraBrasilia.

Godoy, A. S. (2007). Entendendo a pesquisa científica. Gestão do fator humano: uma visão baseada em stakeholders. São Paulo: Saraiva, 351-371.

Gomes, M. V., \& de Sousa, W. D. P. M. (2018). Visão cooperativista dos associados da Cooperativa Crediprata de Moema-MG. Ciências Gerenciais em Foco, 9(6).

Henock, M. S. (2019). Financial sustainability and outreach performance of saving and credit cooperatives: The case of Eastern Ethiopia. Asia Pacific Management Review, 24(1), 1-9.

Hu, Y., Lu, S., Zhang, H., Liu, G., \& Peng, J. (2021). Empirical Analysis on the Performance of Rural Credit Cooperative's Shareholding Reform Based on the Rationale of Isomorphic Incentive Compatibility. Sustainability, 13(5), 2844. 
International Cooperative Alliance (ICA). (2021). Cooperative identity, values e principles. Disponível em: $<$ https://www.ica.coop/en/cooperatives/cooperativeidentity $>$. Acesso em: 10 abr. 2021.

Marchesan, J., Boneti, L. W., \& Tomporoski, A. A. (2019). Cooperativismo como princípio humano. Profanações, 6(Ed. esp.), 212-226.

Mastrocinque, E., Ramírez, F. J., Honrubia-Escribano, A., \& Pham, D. T. (2020). An AHP-based multi-criteria model for sustainable supply chain development in the renewable energy sector. Expert Systems with Applications, 150, 113321. https://doi.org/10.1016/j.eswa.2020.113321

Meinen, Ê., \& Port, M. (2021). Cooperativismo financeiro, percurso histórico, perspectivas e desafios: De cooperativa de crédito a principal instituição financeira do associado. Simplissimo Livros Ltda.

Min, H. (2010). Evaluating the comparative service quality of supermarkets using the analytic hierarchy process. Journal of Services Marketing. https://doi. org/10.1108/08876041011052999

Montegudo, R.M.T. (2001). Revisão dos princípios cooperativistas: democracia da cooperação e a globalização da economia, v.1, São Paulo.

Moraes, J., J. L. A., \& Schwab, P. I. (2019). O papel do cooperativismo no fortalecimento da agricultura familiar. Estudos do CEPE, (49), 67-79.

OCB. Organização de Cooperativas do Brasil. (2018). Relatório de Gestão da Organização das Cooperativas Brasileiras de 2017. Brasília: OCB, 2018.

Organização das Cooperativas Brasileiras (OCB). (2019). OCB moderniza ramos do cooperativismo. Sistema OCB.

Organizaçãodas Cooperativas Brasileiras (OCB). (2018). Anuário do Cooperativismo Brasileiro. Sistema OCB.

Paes, S. M., Souza F. T. A., de Sá Medeiros, H., \& de Souza, D. B. (2019). O Uso da Matriz TOWS para Análise de Estratégias Sustentáveis em Cooperativas. Desenvolvimento em Questão, 17(49), 309-328.

Piletti, D., da Rosa Borges, G., \& Barros, I. C. R. (2015). Os princípios do cooperativismo e o trabalho em equipe em cooperativas de Garibaldi-RS. Navus-Revista de
Gestão e Tecnologia, 5(4), 34-45. https://doi.org/10.22279/ navus.2015.v5n4.p34-45.265

Rahmana, F., Sudjatmoko, A., \& Farmani, A. (2020). The role of cooperative mediation in increasing the number of entrepreneurs: Case study of the DKI credit cooperative. Management Science Letters, 10(6), 1241-1250.

Reus, L. F., dos Santos, A. P. S., Zanela, P. M., \& Yamaguchi, C. K. (2015, November). Panorama dos Modelos de Cooperativas no Brasil. In XV Mostra de Iniciação Científica, Pós-graduação, Pesquisa e Extensão. https://doi.org/10.18226/610001/MOSTRAXV.2015.30

Ribeiro, J. X. P., \& de Oliveira Melo, A. A. (2020). Princípios cooperativistas na percepção dos associados: estudo de caso em uma cooperativa de crédito de Minas Gerais. Latin American Journal of Development, 2(1), 2-23.

Rodríguez, G. A. R., \& de Almeida Santos, F. (2021). Auditoría social en las organizaciones del sector cooperativo: precedente de notable escenario de gobernabilidad. REVESCO: Revista de estudios cooperativos, (138), 45-53.

Saaty, T. L. (2008). Decision making with the analytic hierarchy process. International journal of services sciences, 1(1), 83-98. https://doi.org/10.1504/ IJSSCI.2008.017590

Sales, J. E. (2010). 03) Cooperativismo: Origens e Evolução. Revista Brasileira de Gestão e Engenharia |RBGE| ISSN 2237-1664, (1), 23-34.

Schneider, C. S. (2012). Cooperativa Santa Clara: 100 anos de história. Porto Alegre, RS: SESCOOP.

Schneider, E. P. (2006). Cooperativismo de crédito: organização sistêmica: ênfase no Sistema Sicredi. Dissertação (Mestrado em Economia). Universidade Federal do Rio Grande do Sul. Porto Alegre - RS.

Schneider, J. O. (2012). A doutrina do cooperativismo: análise do alcance, do sentido e da atualidade dos seus valores, princípios e normas nos tempos atuais. Cadernos Gestão Social, 3(2), 251-273.

Silva, E. A. M., Búrigo, F. L., \& Cazella, A. A. (2020) Na Cresol Vale Europeu. Cooperação e Desenvolvimento Rural, 54.https://doi.org/10.5902/1414650940618 
Silva, P., Santos, R. A., \& Oliveira, A. C. D. (2012). Doutrina e princípios cooperativistas: um estudo de caso na cooperativa maxi mundi. Revista Cientifica do ITPAC. Araguaína, Tocantins.
Vronski, M., \& Olimpio, S. M. (2016). Production of the organic cocoa in the amazon: a case study of the amazon organic products cooperative-COPOAM. REBRAE, 9(3), 351-361. https://doi.org/10.7213/rebrae.09.003.AO09. 